\title{
From the Richard N. Farmer to the Peter J. Buckley and Mark Casson AIB Dissertation Award
}

Alan Rugman, University of Reading, UK

\section{History of the AlB Dissertation Award}

The minutes of the AIB "Board of Directors", April 4 to 5, 1986, item 7, report on the formal establishment of the "AIB Annual Doctoral Dissertation Contest." The Board accepted the report of an ad hoc committee established to set guidelines for this contest. The committee was chaired by Hal Mason, the then Executive Secretary of AIB; the other members were Raj Aggarwal, Jeffrey Arpan and Alan Rugman. It appears that previously awards were made by AIB for the best dissertations, with winners including Jose de la Torre, Jeff Arpan and John Daniels. These awards were now formalized.

The AIB Board established a minimum three-member awards committee with a new member replacing the retiring chair each year, as outlined in the current procedures on the AIB website. Eventually the committee was expanded to four members, as some members needed to recuse themselves from assessment of a dissertation from their own institution, or from one they had supervised.

The original, ad hoc committee indicated that all dissertations must deal with subjects directly related to international business including:

1. The theory of multinational enterprise.

2. Business activities which involve international transactions such as international trade and international investment.

3. Interrelationships among enterprise activities and international or foreign environments.

4. Studies of corporative business and management decision making in an international context including studies of the functional and organizational activities of the firm or groups of firms such as licensing, exporting and importing, and other contractual arrangements involving international business.

5. Institutional studies of modes of conducting international business and the disciplines of economics, sociology, political science, law, etc., are welcomed so long as they fit the criteria listed above.

This list of topics probably reflects the 1980s influence of faculty trained in economics, marketing, systems, political science and other cognate disciplines within AIB. The list does not specifically include management of organizations, strategy and entrepreneurship.

Clearly, the field of international business has evolved since 1986, as now the majority of dissertation submissions are in the latter three areas. For example, of the 22 dissertations submitted for the 2013 competition, around 15 used the institution based view (IBV) or some other aspect of "institutional studies", the catchall item 5 in the above list. In contrast, there was only one study specifically advancing the theory of the MNE or other contractual arrangements affecting international business.

The evolution of the field of international business, to include topics in management, organizations, strategy, institutions, etc. is reflected in more recent AIB doctoral dissertation submissions. The respective committee members each year read and evaluate the extended dissertation summaries submitted and select four finalists whose entire dissertations are perused and judged. AIB typically receives over 20 dissertation submissions for the award annually, but has received a significantly larger number of submissions in some years (e.g., 49 submissions in 2009). 
This occurred in 1987 following his untimely death. There were 26 years of the Farmer Award, from 1987 to 2012. In 2013 the AIB Board renamed the AIB Dissertation Award as the Peter J. Buckley and Mark C. Casson AIB Dissertation Award, as discussed later.

\section{The Richard N. Farmer Award}

Richard N. Farmer was a member of the faculty of the Kelley School of Business at Indiana University for 23 years. An internationally known scholar and prolific author, he was considered to be among the founding fathers of international business in the United States. He was one of the founders of the AIB and served as president from 1977-78. After the original endowment was depleted, the AIB continued to fund the award until 2012 in his name with financial support from the Indiana University Center for International Business Education and Research until 2011 and the Michigan State University Center for International Business Education and Research in 2012.

Richard Farmer joined Indiana University in 1964 having completed his doctorate at UCLA. He succeeded Stefan Robock as Chair of the IB department in 1967 and continued in his post until his premature death in 1987. In the 1960s and 1970s Indiana University had as many as twelve IB doctoral fellowships a year and a vibrant program of doctoral education with such IB graduates as Jeff Arpan, Lee Radebaugh, David Ricks, Richard Wright, Kichiro Hiyashi, Paul Korsvold, Chris Korth, Fred Truitt, etc. Overall, some 50 doctoral students graduated and became known as "Farmer's Crop." Many of them were active in the development of AIB, JIBS and international business education at their own institutions.

The Farmer Award recognized both his personal leadership in pioneering doctoral education in international business and also the leadership role of Indiana University in building the world's first major dedicated international business department. More details appear in Rugman (2003), especially Part 1 with essays by Robock, Arpan, Daniels, Ricks and Siffin.

An earlier analysis of the Farmer Awards over the 1991 to 2000 period, by Aggarwal, Petrovic, Ryans and Zong (2008), found that all but two of the thirty-nine dissertation finalists that were selected by the award committees from all submitted dissertations in the 1990s (there were only three finalists in one year over this time period) came from North American universities and that virtually all supervisors were from North American institutions. They also found that the topic coverage largely ignored emerging economies and institutions. The topics were split between the two topic areas of, firstly, economics and finance, and secondly, organizations and management.

By 2013 much greater diversity was apparent. Over the last decade, there have been more international (i.e., non-North American) submissions. The winners for 2012, 2010, 2008, 2007, 2006, 2003 and 2002 have doctorates from European institutions. Previously, the only non-North American winners appear to be Paz Estrella e Tolentino from 1989 and Lena Zander from 1998.
There is also greater diversity in terms of area focus as is illustrated by the 2013 finalist dissertations (for the first time, the 2013 AIB Dissertation Award Committee selected five instead of the traditional four finalists from all submitted dissertations), which covered the following areas:

- Stakeholders in global gold mining firms (award-winning dissertation by Lite Nartey)

- Acquisitions by emerging economy firms in advanced Western economies (finalist dissertation by Hamid Akbari)

- Entrepreneurs and local managers in Russia (finalist dissertation by Elena Kulchina)

- The performance of UK subsidiaries in South East Asia (finalist dissertation by Quyen Nguyen)

- EU carbon credits traded by MNEs (finalist dissertation by Sanjay Patnaik)

This greater diversity of area focus reflects that AIB and JIBS are now truly international.

\section{The Buckley and Casson Award}

In 2013 the AIB Executive Board sought new sponsorship and voted to re-name the AIB Richard N. Farmer Dissertation Award as the Peter J. Buckley and Mark C. Casson AIB Doctoral Dissertation Award. The Award recognizes Peter Buckley as a past president of AIB and his book with Mark Casson in 1976, The Future of the Multinational Enterprise, for its development of internalization theory, which served to bring the analysis of the firm into international business along with the more holistic institutional factors favored by Farmer. Thus, the Award now links firm and institutional factors across the domain of international business. The Award is now sponsored by the Henley Business School of the University of Reading (where Mark Casson is a faculty member) and the Centre for International Business at the University of Leeds (where Peter Buckley is the founding director).

\section{Conclusion}

The Farmer Award was made on 26 occasions, over the 1987-2012 period. All previous AIB dissertation award winners are listed on the following page and a list including all finalists can be found on the AIB website. The winners include many, by now, famous scholars such as Arvind Parkhe, Sri Zaheer, Xavier Martin, Tatiana Kostova, Witold Henisz, Subi Rangan, and others. But the finalists have also produced such outstanding scholars as Julian Birkinshaw, Scott Shane, Miles Shaver, Joanne Oxley, Klaus Meyer, Jaeyong Song, Jennifer Spencer, and many others. We also need to remember that, with typically over 20 dissertations being submitted annually, and up to nearly 50 submissions in some years, there are many productive scholars who have published well, and advanced IB education, even though they were not finalists. 
This is possibly because certain topics seem to go through periods of popularity; from the theory of the MNE, to multinationality and performance, to the IBV and now work on emerging economies.

As the Buckley and Casson award begins its life, with the first five finalists having their dissertation abstracts published along with this article, I am sure that all my colleagues in AIB will wish future generations all the career success which has been signified by the Farmer Award's more than a quarter century of achievement.

\section{References}

Rugman, A. M. (Ed.), 2003. Leadership in International Business Education and Research: Research in Global Strategic Management, Volume 8. Oxford: Elsevier.

Aggarwal, R., Petrovic, V., Ryans, J. K., \& Zang, S., 2008. Outstanding International Business Research: Nature of the Best International Business Dissertations. Multinational Business Review, 16(1); 1-19.

Alan M. Rugman is Professor of International Business and Head of the School of International Business and Strategy at Henley Business School, University of Reading, UK. Before moving to the UK he was at Indiana University, Oxford University, and other leading Universities in North America, Europe and Asia (the triad). From 2004-2006, Mr. Rugman served as President of the Academy of International Business (AIB). Currently he is Dean of the Fellows of AIB.

\section{Previous AIB Dissertation Award Winners}

2012: Marc van Essen (Ph.D. awarded by Erasmus University)

2011: Prithwiraj Choudhury (Ph.D. awarded by Harvard Business School)

2010: Jesper Edman (Ph.D. awarded by Stockholm School of Economics)

2009: Daniel Rottig (Ph.D. awarded by Florida Atlantic University)

2008: Ajai Gaur (Ph.D. awarded by National University of Singapore)

2007: Rekha Krishnan (Ph.D. awarded by Tilburg University)

2006: Jon Erland Lervik (Ph.D. awarded by Norwegian School of Management)

2005: Renata Kosova (Ph.D. awarded by University of Michigan)

2004: Cyril Bouquet (Ph.D. awarded by University of Western Ontario)

2003: Camilla A. Noonan (Ph.D. awarded by University of Reading)

2002: Jeffrey E. Johnson (Ph.D. awarded by University of Strathclyde)

2001: Heather Berry (Ph.D. awarded by University of California, Los Angeles)

2000: Joan P. Mileski (Ph.D. awarded by University of Texas at Dallas)

1999: Witold Henisz (Ph.D. awarded by University of California, Berkeley)

1998: Lena Zander (Ph.D. awarded by Uppsala University)

1997: Tatiana Kostova (Ph.D. awarded by University of Minnesota)

1996: Xavier Martin (Ph.D. awarded by University of Michigan)

1995: Subramanian Rangan (Ph.D. awarded by Harvard University)

1994: Patricia Robinson (Ph.D. awarded by Massachusetts Institute of Technology)

1993: Scott Xianfang Liu (Ph.D. awarded by Pennsylvania State University)

1992: $\quad$ Srilata Zaheer (Ph.D. awarded by Massachusetts Institute of Technology)

1991: Eugene Salorio (Ph.D. awarded by Harvard University)

1990: $\quad$ Arvind Parkhe (Ph.D. awarded by Temple University)

1989: Paz Estrella e Tolentino (Ph.D. awarded by University of Reading)

1988: Ching-Sung Wu (Ph.D. awarded by University of California, Los Angeles)

1987: Fritz Rieger (Ph.D. awarded by McGill University)

1986: Kwang Chul Lee (Ph.D. awarded by University of South Carolina) 